\title{
The Strategic Group Analysis of BYD New Energy Vehicles From the Perspective of Value Chain
}

\author{
Tong $\mathrm{An}^{*}$
}

\author{
School of Economics and Management, Beijing Jiaotong University, Beijing, China \\ *Corresponding author. Email: 19120688@bjtu.edu.cn
}

\begin{abstract}
A new energy vehicle is an irresistable trend, which is the guidance and goal of the automobile industry's future development. BYD as a pioneer and strong performer among domestic new energy vehicles, has received extensive attention of the society from all walks of life. This paper takes BYD as the core developing a strategic group analysis on the new energy automotive industry. First of all, this paper based on the perspective of value chain of new energy vehicles line divides the strategic groups and to clarify BYD's position and competitive environment in the industry. And then through an analysis of the internal and external competition strategy group at the same time to find out the advantages and disadvantages of BYD in the competition, and put forward development prospects.
\end{abstract}

Keywords: BYD, Strategic groups, Value chain, New energy vehicle.

\section{INTRODUCTION}

With the continuous enhancement of people's awareness of environmental protection, the new energy automobile industry has been widely concerned [1]. At the same time, the emergence and development of new energy vehicles has made the traditional automobile industry glow with new vitality and become a new breakthrough point for the automobile industry. Up to now, there is still a big gap between China and developed countries in traditional automobile industry. The emergence of new energy vehicles drives a new round of global competition, providing a new competitive platform and a chance to seize the high point for China's automobile industry [2].

BYD is one of the well-known domestic independent automobile brands. As the pioneer and leader of China's new energy vehicles, it has received national policy support and wide attention from all sectors of society, which is in an important place in the new energy automobile industry. At present, BYD has fully mastered the technology of new-energy vehicles. According to the 2019 annual report released by BYD, the company's annual revenue in 2019 was about 127.739 billion yuan, down $1.78 \%$ year-on-year, while the R\&D investment increased $12.83 \%$.

In consideration of the epidemic, the withdrawal of new energy vehicle subsidies and other factors, BYD's revenue is only slightly lower, this performance is very good [3]. However, the new energy automotive industry is still an emerging industry, before the industry matures, the barriers to entry are low, which makes the existing enterprise face more variables, threat and challenge. If enterprises want to extend or keep their advantage position, they need to make constant adjustments and efforts for the market and competitive environment. The strategic group analysis in this paper can clarify BYD's position in the current competitive environment more clearly, which can draw the current development advantages and disadvantages of BYD and look forward to the future development of BYD.

\section{REVIEW OF RELEVANT THEORIES}

\subsection{Strategic Groups}

Strategic groups were put forward by Michael Porter in 1980. He believed that strategic groups could be divided by considering a certain combination of characteristics, and environmental opportunities and threats could be determined according to different strategic groups. Enterprises belonging to the same strategic group have more competition, while those not belonging to the same strategic group or those far apart from each other in the figure have less competition. 
In addition to the attention of competitors within the same strategic group, the possibility of migration of the enterprises in other strategic groups should also be considered. However, there are barriers to strategic migration [4]. The barriers to migration are factors that limit the transfer of enterprises between different groups within an industry. If the transfer barrier is low, the entry threat is high; If the migration barrier is high, the entry threat is low [5].

\subsection{Value Chain}

The theory of value chain was first put forward by Michael Porter in his book Competitive Advantage in 1985. Value chain is the general term of a series of economic activities conducted by enterprises to create value for customers, shareholders, employees and other interest groups, and the difference of value chain among different enterprises forms the source of enterprises' competitive advantage [6].

In the past, scholars mainly used the "diamond model" to study the competitiveness of new energy vehicles, analyze the advantages and disadvantages from the six elements of the model, and put forward countermeasures from the macro and micro perspectives. The application of value chain in the new energy automobile industry mainly focuses on the discussion of business model and energy supply model, and few literatures are used to study the competitiveness of a single enterprise. This paper taking BYD as the core, stands on the strategic groups to analyze BYD's position and competition in the industry. And then this paper creatively takes value chain extension direction as one strategic group division dimension, which is a good way to identify different strategic groups.

Based on the characteristics of the energy automobile industry, this paper divides the activities of the value chain into four links: technology and vehicle $\mathrm{R} \& \mathrm{D}$, production and manufacturing, sales and aftersales service. These links are respectively reflected in several aspects, as shown in the figure 1 below.

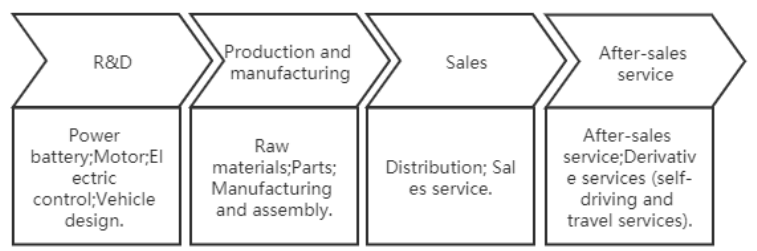

Figure 1 Value chain of new energy automobile industry

\section{STRATEGIC GROUP DIVISION}

\subsection{Dimensions Selection}

At present, one major trend of China's new energy automobile industry is that new energy automobiles will extend up and down the value chain of the automobile industry, and the industrial profit structure is changing accordingly [7]. The upstream power battery and intelligent technology, as well as the downstream endmarket user service will become the important profit pool [8].

According to the China's new energy automobile development report: 2020, we can get the sales of new energy automobile enterprise, respectively BYD is $19 \%$, Tesla China $14.8 \%$, SAIC $6.7 \%$, GAC6.5\%, BAIC $5.6 \%$, BMW Brilliance $5 \%$, Chery3.5\%, Great Wall Automobile3\%, Geely Automobile2.4\%, NIO 4.5\%, X Motors $1.3 \%$, WM Motor $2.5 \%$.

Enterprises with similar nature basically have similar scale in the new energy vehicle market. This paper divided 12 companies according to market share and the enterprise features into several groups. The first group is industry leader including BYD and Tesla. The second group is China's well-known joint venture including SAIC, GAC, BAIC and BMW Brilliance. The third group is China's traditional independent brand including Chery, Great Wall Automobile, Geely Automobile. The forth group is the new forces including NIO, X Motors, WM Motor. Next, we consider the positions of the groups in the strategic group map in terms of group position units.

According to the China New Energy Vehicles Development Report: 2020, we can get the sales volume of auto companies in the first quarter of 2020. Due to the diversity of automobile market segments, car companies with different sizes or market share have less competitiveness. For new-energy vehicles, market share is a more appropriate dimension to divide strategic groups.

According to the current situation and development trends of new energy automobile industry, it can be found that the dimension of extending to the upper reaches of the value chain and extending to the value chain can better distinguish the strategic groups using different strategies. Besides, the complexity of New energy vehicle industry is high. It's reasonable to take enterprise value chain extension direction to divide, which can also be clearly showed a strong competitive relationship of enterprises and weak competition and potential competition of enterprises.

Therefore, this paper takes the current enterprise in the value chain extension direction and market share of as two dimensions of strategic group analysis. 


\subsection{Strategic Group Location Analysis}

\subsubsection{The Upstream of the Value Chain with $R \& D$ and Production as the Core}

As a traditional independent brand, BYD is also a pioneer of new energy vehicles. It has great advantages in the upstream of the value chain, especially in the $\mathrm{R} \& \mathrm{D}$ links. BYD's most brilliant advantage is in the battery field. BYD has $100 \%$ independent R\&D, design and production capacity. With more than 20 years of continuous innovation, products have covered consumer 3C batteries, power batteries, solar cells, as well as energy storage batteries and other fields, and formed a complete battery industry chain. In addition, BYD's electric car's three-electric system and vehicle platform are independently developed, and the level of matching test is higher than that of most automobile brands, including Tesla [9]. BYD has already announced that it will open up its three-power system and start supplying other car companies with its E-platform, which is a sign of BYD's confidence in its technology [10]. In the production link, influenced by scale and maturity, no matter in the cost or precision, BYD do have a gap with international brands. But as a domestic well-known brand, after years of accumulation, production link is not BYD's disadvantage. In general, BYD's advantage in the upstream value chain is very clear.

Tesla, second only to BYD in sales volume in China, has its own advantages in R\&D, vehicle manufacturing and production. In terms of $\mathrm{R} \& \mathrm{D}$, Tesla has excellent battery management technology, which can manage the charge and discharge of 7-8 thousand independent batteries. Tesla also addresses two factors that affect battery life: inconsistent discharge and heat dissipation. However, as the cost of sheet aluminum-plastic lithium batteries has come close to that of columnar batteries, the advantages of Tesla's battery management system may gradually be lost. It's advantages in extending upstream of the value chain will become smaller. However, in terms of vehicle design, it stands out with its unique futuristic appearance design, which has attracted a large number of followers. By contrast, BYD's exterior and interior look more down-to-earth and more modern than Tesla's.

SAIC, GAC, BAIC, BMW Brilliance Automotive and other joint ventures have a certain market share in the field of new energy vehicles. However, joint venture brands, especially SAIC and BMW Brilliance, are always reluctant to compete with their most advanced technology. Although they are designing and developing their own battery packs and battery management systems, they currently rely on suppliers for their threepower systems, either because of government subsidies or their own immature technology. These companies purchase a complete battery pack and management system. On the one hand, technology depends on other companies. On the other hand, cost compression is difficult. BYD can get cost leadership in technology [11]. In the whole vehicle design and production, depending on a higher level of aesthetic design and maturity of the production line, this kind of enterprise will have certain advantages. On the whole, compared with BYD, the joint venture has a smaller advantage in the upstream of the value chain and has a smaller degree of expansion up the value chain.

For Chinese traditional independent brands such as Geely, Great Wall Automobile and Chery, some attempts have been made in the field of new energy. However, except for BYD, most of the main engine factories of independent brands in China do not have their own design ability of battery pack and battery. They still invest less in the R\&D of new energy vehicles, especially Geely and other private enterprises without obvious national policies inclination and battery technology foundation. They are still not clear about the strategic layout of new energy vehicles.

Without brand accumulation, it is not easy for some new forces of car making to quickly establish their reputation in the field of new energy vehicles. Representative NIO, X Motors, WM Motor all have excellent market performance [12, 13]. They have a small advantage in the upstream of the value chain, especially in the aspect of R\&D, but in the aspect of vehicle design, they pay attention to personalized design, cater to the niche market, actively give play to their differentiation advantages, and have a strong product matrix.

\subsubsection{Downstream of the Value Chain with Sales and After-sales as the Core}

Under the background of the Internet era, the application of Internet thinking is an advantage engraved in their genes. In terms of sales and after-sales services, Tesla adopts the direct sales model, which includes experience stores and online direct sales channels. Through this model, the service level is guaranteed and all customers have the best experience in the whole chain from the beginning to the end. Tesla subverts the marketing model of traditional cars and inspires the entire automobile industry with Internet thinking. NIO's sales model is similar to Tesla's. The sales function basically depends on the online channel, while the offline function is more about brand display and user experience. Unlike NIO, X Motors' sales channels are not limited to self-built. In addition to its own official mall, $\mathrm{X}$ Motors also opened online shopping malls in Tmall. WM Motor generally adopts the channel model of franchising as the main channel and direct marketing as the auxiliary channel.

For traditional car manufacturers, although $4 \mathrm{~S}$ stores are widely criticized for their service level, especially 
for domestic independent brands, they still basically use $4 \mathrm{~S}$ stores for distribution. The reason is that many traditional fuel-powered cars largely rely on the service of $4 \mathrm{~S}$ stores, and there are historical burdens and obstacles to abandon this sales model. In addition, in terms of derivative services, X Motors, NIO and Tesla have also developed autonomous driving and other auxiliary services. Therefore, BYD does have some disadvantages compared with Tesla, NIO and other companies in terms of sales cost and user experience in sales and after-sales.

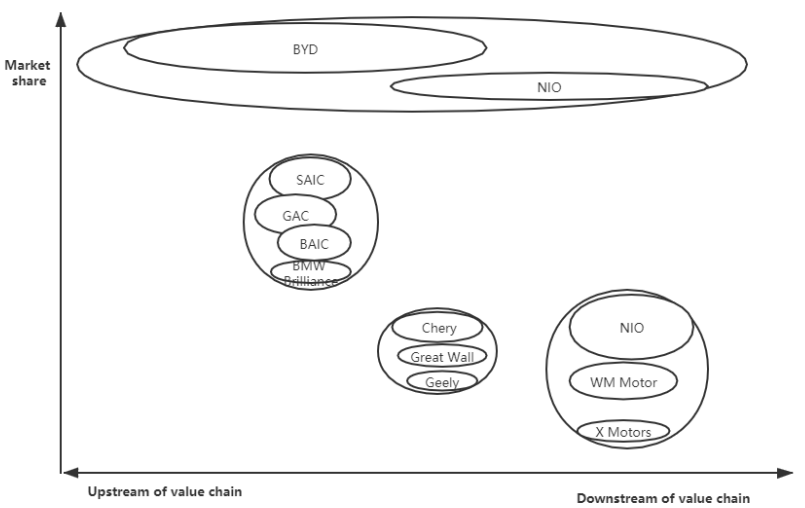

Figure 2 Strategic group

\section{ANALYSIS OF STRATEGIC GROUP COMPETITION}

\subsection{Analysis of Intra-strategic Group Competition}

According to the strategic group chart, it can be seen that BYD and Tesla belong to the same strategic group. Tesla is an enterprise with a particularly clear strategy. Adhering to the differentiation strategy, Tesla has only delivered four cars to Volkswagen since its establishment in 2003, namely, Tesla Roadster, Models, Model M and Model 3. The Model 3, priced at 300, 000 yuan, is Tesla's mass-market car. Tesla operates in the ultra-high-end, high-end and mid-end markets, and performs well in each segment.

In the upstream of the value chain, Tesla is unable to achieve three-power independence, but it has a topnotch battery management system. However, this advantage will disappear with the reduction of the cost of sheet aluminum plastic lithium batteries. BYD has a great advantage. In the downstream of the value chain, Tesla has always been favored by the public with its novel sales model, good purchase experience and aftersales service. BYD appear some relative shortage in the layout of the downstream of the value chain. The first shortage is basic service, including supporting services and after-sales service, which has long been notorious for poor service of domestic vehicles. The second shortage is derivative services, such as travel services, Internet services, and even unmanned system. BYD doesn't give enough attention and strategic layout in downstream of the value chain.

All in all, in the upstream of the value chain, BYD's advantage is obvious and will continue to exist, while Tesla's advantage will gradually disappear. But down the value chain, where BYD doesn't have a clear strategy. Of course, this is also related to the market strategy of the company itself. Tesla firstly played the high-end market. After "robbing the rich to help the poor", it began to enter the mid-end market after accumulating certain capital. BYD, on the other hand, has been engaged in intensive cultivation in the middle and low end of the market, constantly optimizing the vehicle manufacturing system and three-power system, and gradually producing middle and high-end cars. Tesla model3 has gone head-to-head with BYD's Han $[14,15]$.

In terms of the formal confrontation between BYD and Tesla in the middle and high-end market, it also announced the urgency of BYD's entire value chain layout. While continuing to meticulously develop the upstream of the value chain, the value chain terminal is also a necessary change for BYD to enter the middle and high-end market successfully.

\subsection{Analysis of Competition among Strategic Groups}

Joint ventures SAIC, GAC, domestic enterprises Chery, private enterprises Geely and other joint ventures as well as traditional independent brands occupy a certain market share in the new energy market, but this is strongly correlated with their brand precipitation. In the upstream direction of the value chain, especially the transfer of R\&D links has high barriers, the transfer to the downstream of the value chain does not have an obvious advantage, the threat to BYD is low.

NIO, X Motors, WM Motor, and other outstanding enterprises in the value chain terminal adopt the model of direct sales to ensure the service level, and better meet consumers' purchase service experience requirements in terms of sales and after-sales service. These companies' efforts in the value chain terminal are conducive to better understanding market demands, rapidly producing differentiated products through timely response, integrating rapid iterative Internet thinking into automobile design. In the aspect of technology R\&D, especially in the aspect of three-power technology, such enterprises have natural disadvantages and it is difficult to move upstream to the value chain.

There has been a shift among strategic groups. The other three strategic groups are all moving up the value chain to varying degrees, especially the joint venture brands, but this is a very slow process. When they want 
to move up the value chain, they will find the migration barriers are high. They need to put in a lot of time, energy and capital, and this is BYD's advantage as a pioneer [16].

Under the condition of no brand of precipitation, some new forces obtained a considerable market share in a relatively short time, which shows the importance and enormous potential value of the downstream and the terminal of value chain. And this also conforms to the smiling curve. BYD in this respect has shown a greater lack. Fortunately, it is less difficult to extend to the lower reaches of the value chain. When BYD moved to the new power group, the barriers are low. BYD needs to pay attention to the strategic layout of the lower reaches of the value chain, and actively use the Internet thinking and put into practice [17].

\section{CONCLUSION}

The development of the automobile industry plays an important role in the national economic development. However, in the traditional automobile industry, China's independent brands are at a backward stage. And new energy vehicles are an opportunity for China to take a leading position in the automobile industry. China attaches great importance to the new energy automobile industry. The adoption of this subsidy has indeed effectively fostered and protected the initial development of new energy vehicles and the industry. With the reduction and withdrawal of subsidies, the new energy vehicle industry is facing a certain plight. But in recent years, BYD got a good technology research and development environment from the government subsidies independent development of the three-power system.

This paper through BYD's strategic group analysis, clears the BYD's position in the industry, and analyzes the advantages and disadvantages of the BYD. BYD has obvious advantages in the upstream of value chain. BYD's layout in the lower reaches of the value chain is somewhat inadequate. BYD should pay attention to the layout of the downstream of the value chain, can help BYD in shock in the high-end market more competitive, eventually became one of the best layout of the whole industrial chain. It is believed that BYD will become better and better in the future development and continue to become the leader of China's new energy vehicles.

\section{ACKNOWLEDGMENT}

This work was supported by the [Major Program of The National Social Science Fund of China \#1] under Grant [No. 15ZDA022].

\section{REFERENCES}

[1] Zhou Dan. China's new energy vehicle industry development trend [J]. Sino-Global Energy, 2018, 23(02):26.

[2] Yan Bo. Overview of new energy vehicle technology development and trend [J]. Modern Business Trade Industry, 2018, 39(35):12-16.

[3] Gilmar Masiero, Mario Henrique Ogasavara, Ailton Conde Jussani, Marcelo Luiz Risso. Electric vehicles in China: BYD strategies and government subsidies[J]. RAI Revista de Administração e Inovação, 2016, 13(1).

[4] Mónica García-Ochoa Mayor, Nuria Bajo Davó, Félix Roux Martínez. Dynamic strategic groups' analysis and identification of mobility barriers in the European mobile phone industry [J]. Int. J. of Technology Management, 2016, 71(3/4).

[5] George Panagiotou. Managerial cognitions of competitive environments: a strategic group analysis[J]. Management Research News, 2006, 29(7).

[6] Zhou Yali, Liu Juanjuan. Analysis on the competitiveness of China's new energy automobile industry based on value chain $[\mathrm{J}]$. Jiangsu Commercial Forum, 2014(11):73-76.

[7] Chao Ye, Ye Chao, Xu Huawei, Hu Jianyao, Peng Qi, Yang Lin. Research On Technology Development Status and Trend Analysis Of New Energy Vehicle[J]. IOP Conference Series: Earth and Environmental Science, 2020, 558(5).

[8] Wang Xiaofeng, Yu Zhimin. Development status and trend of New energy vehicles in China [J]. Science \& Technology Review, 2016, 34(17):1318.

[9] Zhang Jun, Xiao Qian, Meng Qingkuo. Analysis on the development status and trend of new energy vehicle driving motor [J]. Auto Industry Research, 2018(06):43-47.

[10] Zhao Jianlin. Byd will lead the new energy battery technology revolution, opening up strategic advantages will show [J]. Commercial College, 2020(05):108.

[11] Shi Longlong, Zheng Peng. Byd cost management practice: from the perspective of value chain integration $[\mathrm{J}]$. Finance and Accounting (Finance Edition), 2012(02):17-18.

[12] Tian Zhilong, Li Chunrong. The business strategy of the weak later-entrant in China's auto market -Based on the case analysis of Chinese cars such as 
Geely, Chery, Brilliance, BYD and Hafei [J]. Management World, 2010(08):139-152+188.

[13] Wang Yong. The second half decisive battle of the new forces building cars [J]. Energy, 2020(09):3033.

[14] Dong Xiaojing. A Comparative Study on the international path between BYD and Tesla in new energy vehicles [D]. Jiangxi University of Finance and Economics, 2020.
[15] Gong Zhiguo. Byd auto Marketing strategy analysis [D]. Jilin University, 2010.

[16] Sun Juncheng, Zhou Qi. Construction of core Competitiveness system of electric vehicle enterprises based on value chain [J]. Journal of Donghua University (Natural Science), 2018, 44(06):995-1001.

[17] Jia Yuzhu. Value chain analysis of BYD's vertical Integration model $[\mathrm{J}]$. Foreign Economic and Trade, 2013(01):114-115+141. 